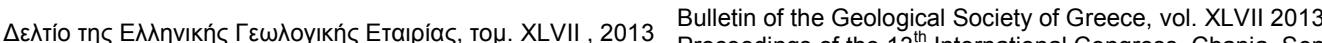

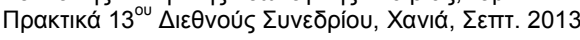

\title{
IMPROVED EARTHOUAKE LOCATION IN THE AREA OF NORTH EUBOEAN GULF AFTER THE IMPLEMENTATION OF A 3D NON-LINEAR LOCATION METHOD IN COMBINATION WITH A 3D VELOCITY MODEL
}

\author{
Mouzakiotis E. ${ }^{1}$ and Karastathis V. K. ${ }^{1}$ \\ ${ }^{1}$ National Observatory of Athens, Institute of Geodynamics, aggelmo@geol.uoa.gr, \\ Karastathis@noa.gr
}

\begin{abstract}
Considerably improved hypocentral locations of the 274 earthquakes, with magnitudes between 1.5 to $4.1 \mathrm{Ml}$ recorded during the period from 2009 to 2010 by the Hellenic Unified Seismographic Network (HUSN), have been obtained for the area of North Euboean Gulf after the implementation of a $3 D$ non-linear location algorithm and a previously calculated local $3 D$ velocity model for both $P$ and $S$ wave phases. To assess the effectiveness of the $3 D$ locations we compared the results with the solutions obtained with alternative $1 D$ velocity models such as the minimum $1 D$ model calculated with the VELEST algorithm and the $1 D$ model used by the National Observatory of Athens (NOA) for daily earthquake analysis. We were further able to assess the location accuracy of each model by comparing the location results for a number of quarry blasts that occurred in the area in that period. The use of the local $3 D$ velocity model provides considerably more accurate than the minimum $1 D$ model which in turn provides more constrained locations from the $1 D$ model of NOA. The epicentral locations calculated by each model are almost similar; however the depth distribution of the events varies, with depth differences of up to $12 \mathrm{~km}$ for some earthquakes. The results prove that accurate, local models are necessary in order to achieve more accurate locations for the events in a local area.
\end{abstract}

Key words: Relocation; Euboean Gulf Seismicity; Central Greece.

\section{Пєрí $\eta \psi \eta$}

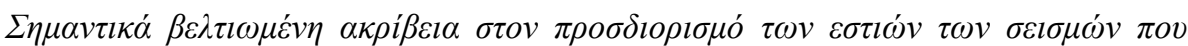

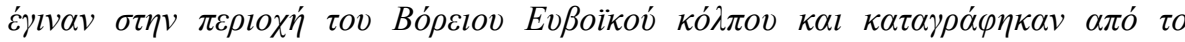

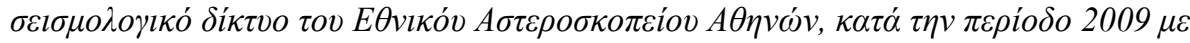

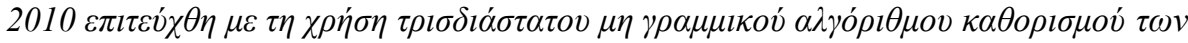

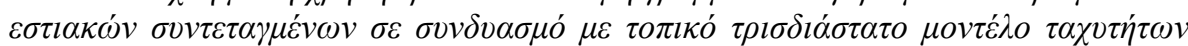

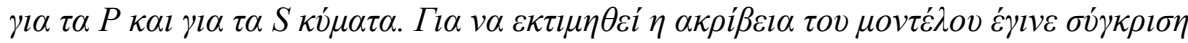

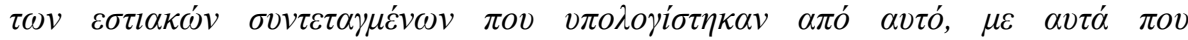

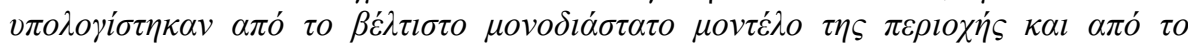

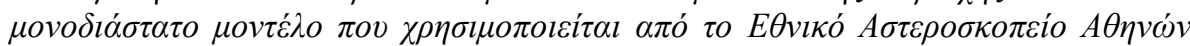

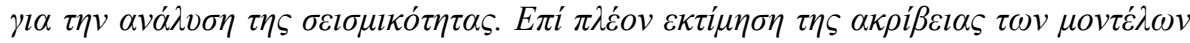

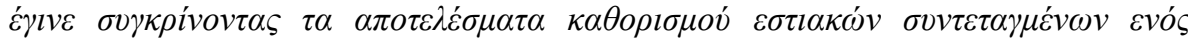




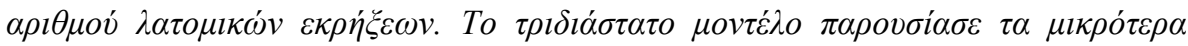

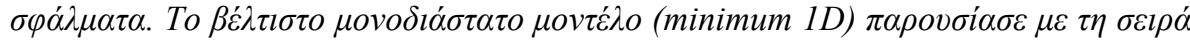

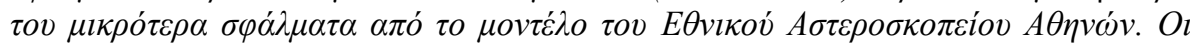

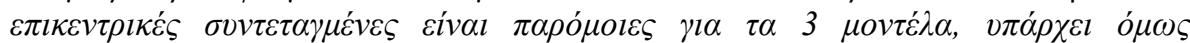

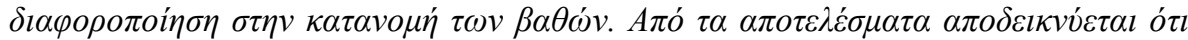

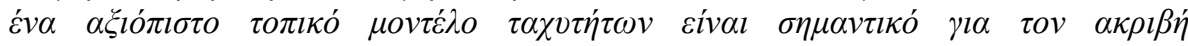

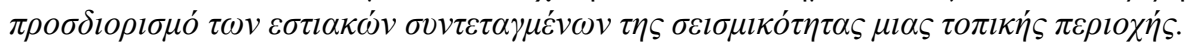

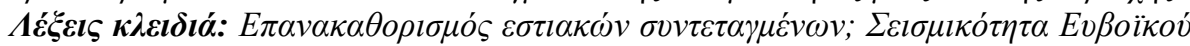
$\kappa o ́ \lambda \pi o v ; K \varepsilon v \tau \rho \imath \kappa \dot{~} E \lambda \lambda \alpha ́ \delta \alpha$.

\section{Introduction}

Inadequate knowledge of the earth's velocity structure can lead to systematic errors in hypocentral location of the earthquakes (Douglas, 1967; Dewey, 1971, 1972; Engdahl and Lee, 1976; Jordan and Sverdrup, 1981; Pavlis and Hokanson, 1985; Pavlis, 1992) and it can subsequently lead to incorrect evaluation of earthquake spatial patterns. This problem is more severe in cases of small local earthquakes, since they are usually recorded only locally, where the velocity structure can be much different than the average velocity structure of the region covered by the seismographic network. The construction of three-dimensional models is required to correctly calculate the ray paths, however, is not always feasible, since their calculation requires dense and well distributed seismicity. Therefore in most cases for the regional seismicity monitoring the data are analyzed with the use of $1 \mathrm{D}$ velocity models, representing the average velocity structure of the earth's crust in a regional scale.

In this study we assess the performance of the 3D velocity model for the area of North Euboean Gulf, previously calculated by Karastathis et al. (2011), in locating earthquakes. This is accomplished by relocating the seismicity data of the Hellenic Unified Seismographic Network (HUSN) for this particular area and for a two years period between 2009 and 2010 . The results were assessed by comparing the location results of quarry blasts and by examining the error ellipsoids and the event spatial distribution. It is important to note that the seismicity data used for the evaluation of the model are totally independent to the ones used for the calculation of the 3D model.

\section{Tectonics}

The area of the North Euboean Gulf (Figure 1) is located in central Greece, between two major structures: the North Aegean Trough and the Gulf of Corinth. The area itself contains a number of notable fault zones. The most important and well documented fault structure is the Atalanti fault zone (Poulimenos and Doutsos, 1996; Ganas 1998; Pantosti et al., 2001; Karastathis et al., 2007; Pavlidis et al., 2004) with a NW-SE strike. Two other notable fault zones are the Kamena Vourla fault zone and the Kallidromo fault zone, north of the Atalanti fault zone. Additionally, the Knimis fault zone (Jackson et al. 1982) and some additional smaller fault zones in Malesina peninsula with NE-SW direction (Palyvos, 2001) appear in the area.

\section{Methodology and Data}

Data from seven local stations belonging to the HUSN network, plus the additional station of CHLKS, installed for the seismic monitoring of Athens, were utilized in this study (Figure 1). These stations were the ones within the $3 \mathrm{D}$ velocity model area. Although we could not use the outer stations, the information loss was not significant since the most of the events were of low magnitude $(<3 \mathrm{Ml})$ and recorded only locally. 


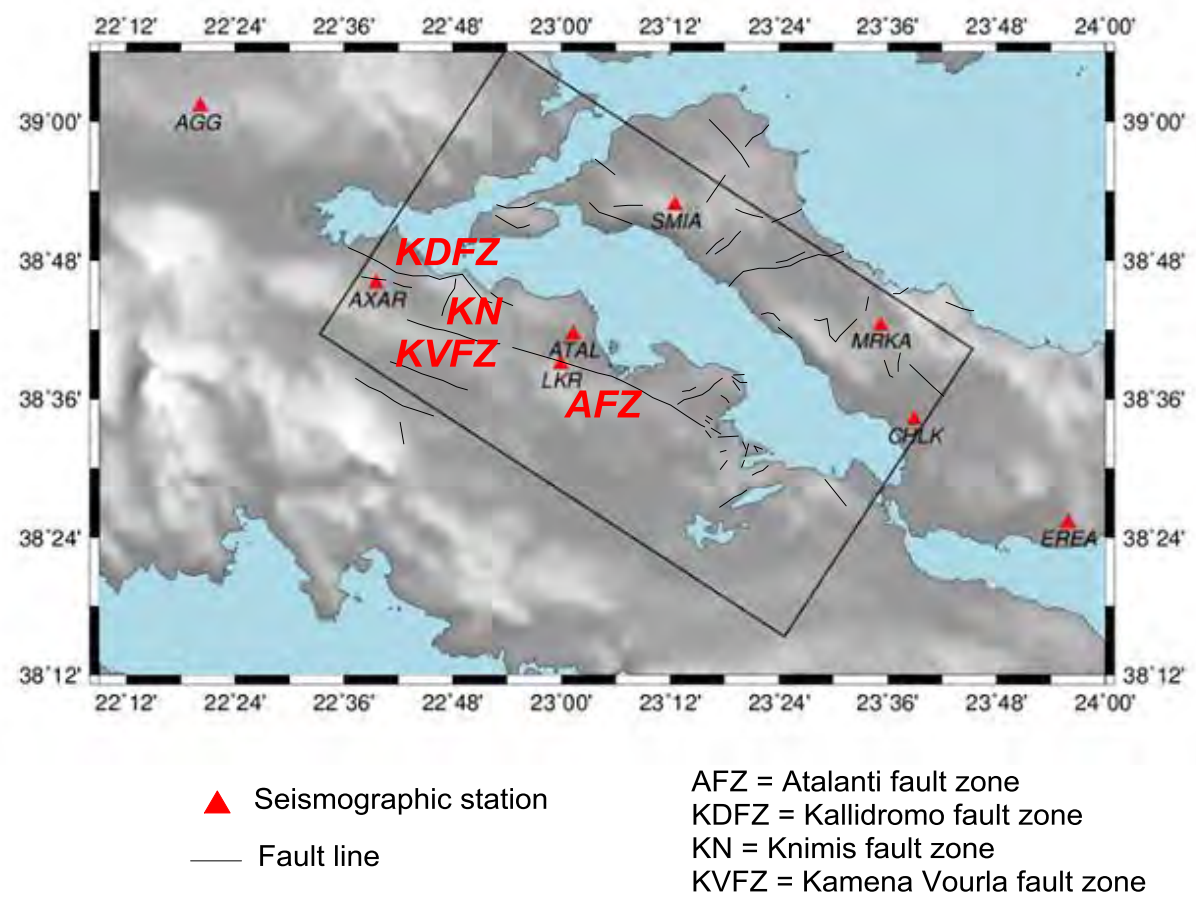

Figure 1 - The study area, the stations that were incorporated and the major fault zones (Institute of Geology and Mineral Exploration - IGME, 1993; Jackson et al., 1982; Palyvos, 2001; Tzanis et al., 2009).

In total 274 events were recorded with magnitudes larger than $1.5 \mathrm{Ml}$. The events recorded by five local stations at minimum. We selected the 217 most reliably located events, with azimuthal gap lower than $180^{\circ}$ and with at least $5 \mathrm{P}$ and $3 \mathrm{~S}$ wave phases. Many of the phases used have been obtained by NOA's bulletins and then revised when necessary. The dataset was completed with other local phases not previously considered by NOA after manual picking.

The 1D velocity models utilized are: a) the 1D velocity model used for daily earthquake analysis by NOA, b) the minimum 1D velocity model calculated by VELEST algorithm (Kissling, 1995) by Karastathis et al. (2011) (Figure 2). The 3D velocity model (Figure 3) was suggested by Karastathis et al. (2011) using a dataset acquired by a local seismographic network including 24 land and 6 OBS stations. The creation of the model was based on a successive application of the 1D minimum velocity model algorithm (Kissling et al., 1994) and linearized 3D inversion (Thurber, 1989; Emberhard-Philips, 1990).

To accurately locate the earthquakes, the probabilistic non-linear location method provided by the NonLinLoc software package was implemented. The velocity model is imported as a cubic grid with a velocity value in each node. Travel-times between each node and each station are calculated using a 3D version (Le Maur, 1994; Le Maur et al., 1997) of the Eikonal finite difference scheme (Podvin and Lecomte, 1991).

The complete location probability density function (PDF) is accurately obtained by the Oct-Tree importance sampling algorithm, which is based on recursive subdivision and sampling of cells in 3D space. Location PDF is calculated using the Equal Differential Time function (Lomax, 2005), which is robust in the presence of outlier data: 


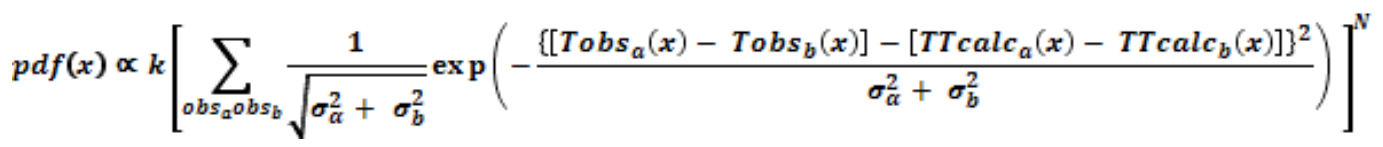

This method is not depended on the origin time, thus reducing the initial $4 \mathrm{D}$ problem to a $3 \mathrm{D}$ search over latitude, longitude and depth.

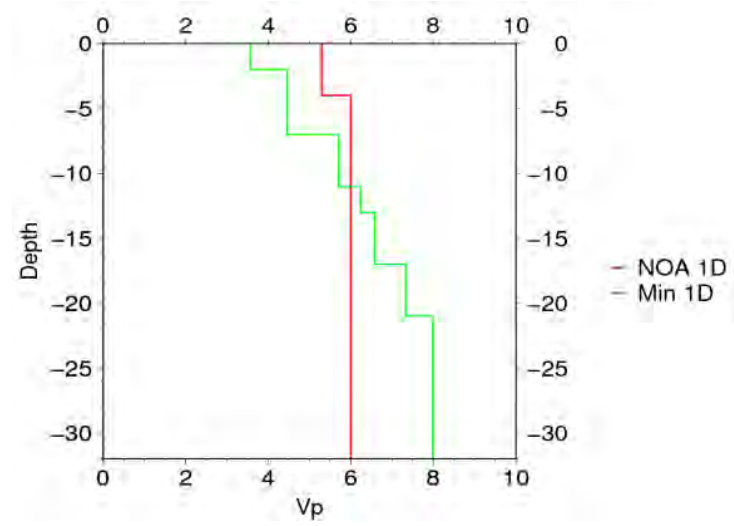

Figure 2 - NOA 1D (red line) and the minimum 1D (green line) models used in the study.
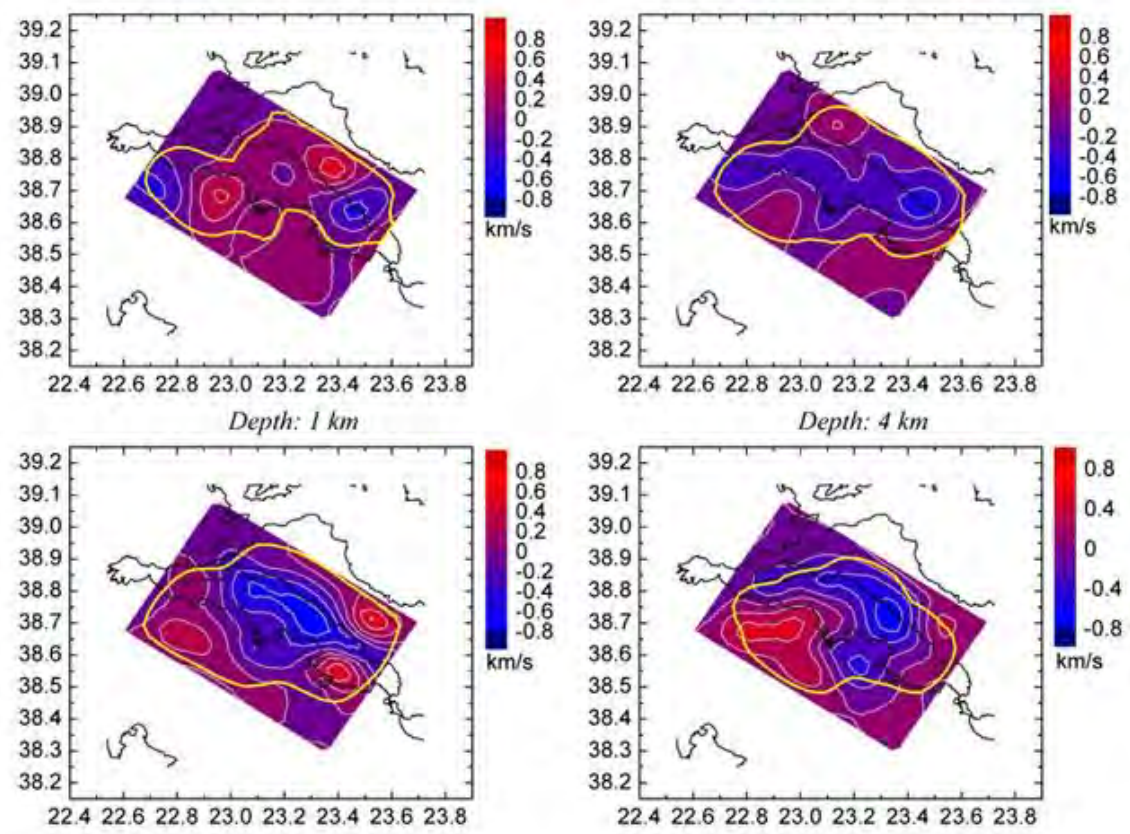

Figure 3 - Local normalized 3D velocity model (Karastathis et al., 2011).

\section{Results}

Each model's validity was initially assessed by locating three quarry blasts, shot in the Tragana area and recorded by the HUSN network. The locations of the blasts given in the NOA's catalog as it can be seen in Figure 4 are obviously far from the actual site of the quarry. 
The 1D minimum model concentrated the blasts at the same position but epicenters are systematically mislocated to the south by approximately $7 \mathrm{Km}$. This was expected due to the lack of seismographic stations south of the quarry. In spite of this limitation, however, the three blasts were accurately located within the quarry, when using the local 3D model. These results prove the validity of the model in a local scale.

The next step was to evaluate the model by a direct comparison of the location results of the seismicity with those obtained by the $1 \mathrm{D}$ models. The results proved that the $3 \mathrm{D}$ model achieved significantly better constrained event locations, compared to the other two models. In turn the minimum 1D model provided more constrained locations compared to the NOA 1D model. The average confidence ellipsoid volume was $55.4 \mathrm{Km}^{3}$ for the $3 \mathrm{D}$ model, $78.9 \mathrm{Km}^{3}$ for the minimum 1D model and $106 \mathrm{Km}^{3}$ for the NOA 1D model. The average major semi-axis lengths were 4.8 $\mathrm{Km}, 5.3 \mathrm{Km}$ and $6.8 \mathrm{Km}$, respectively, for the 3 models (Figure 5).

It is worth to note that despite the small number of seismographic stations, we obtained highly constrained event locations for a large number of events, mainly in the central area, where the azimuthal coverage was optimal. Thus, the unrealistic results given by the usual RMS error minimizing procedure were considerably eliminated.

The results did not show any significant shift in the epicentral distribution for most of the events, between the 3 models (Figures 6,7). The picture however is quite different for the distribution of

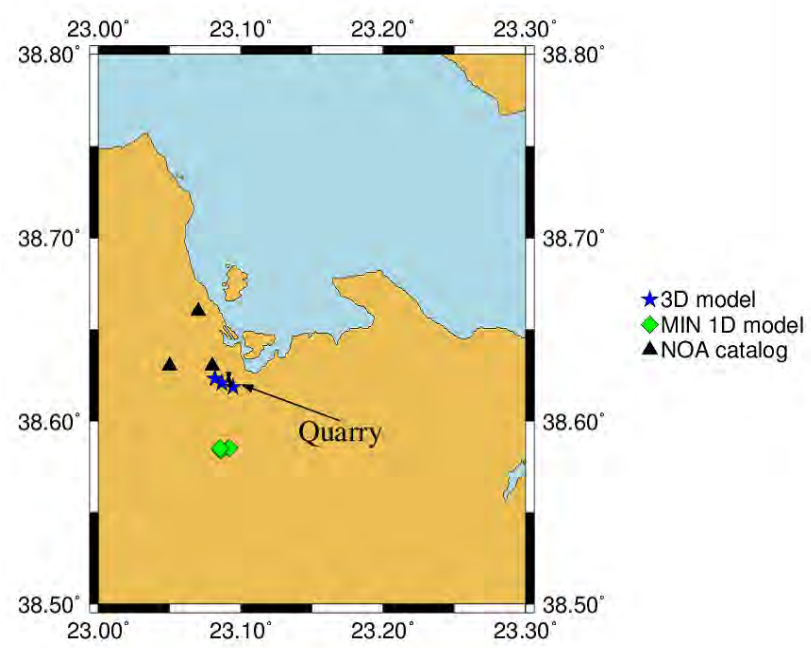

Figure 4 - Map showing the location of the quarry blasts as obtained by the NOA's catalogue (black), the minimum 1D model (green) and the 3D model (blue).

the hypocentral depths between the 3 models, as seen in Figure 8. For the NOA 1D model this distribution is quite unrealistic with a large number of events being located above the depth of 2 $\mathrm{Km}$. The minimum 1D model showed an almost symmetrical distribution centered around the depths of 10-12 Km with the majority of the events being located between 6 to $14 \mathrm{~km}$. For the local 3D model most events are located within 6 to $12 \mathrm{~km}$. The number of events increases almost linearly from 2 to $12 \mathrm{~km}$ and then drops rapidly, which indicates that the brittle-ductile transition zone is at this depth. We can see from the results that the majority of the seismicity is located on the western coast of the island of Euboea (Figure 9). The rest of the events are concentrated at known fault areas. The two clusters in the NW part of the area are probably related to the Knimis and Kalidromo fault zones. An exception is the cluster located offshore, east of Malesina peninsula since the seismicity cannot be safely related to the Atalanti fault. The possibility that this cluster is 
related to an active zone at the opposite coast cannot be dismissed. Finally no significant seismicity appears to be attributed to the major fault zone of Atalanti.
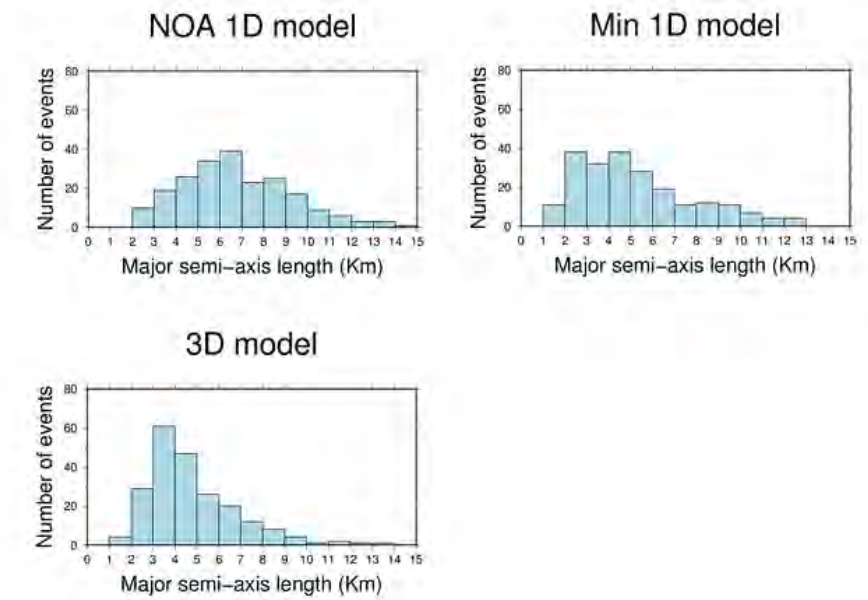

Figure 5 - Distribution of the major ellipsoid semi-axes for the NOA 1D model (top left), the minimum 1D model (top right) and the 3D model (bottom left).

The results proved clearly that the local $3 \mathrm{D}$ velocity model is valid for the area and could assist towards more accurate hypocentral locations. As it has already been mentioned, the velocity model has been calculated on the basis of a totally different dataset, with different stations, event locations and ray coverage. The successful location of the earthquakes is an indicator of the independency of the model from the initial dataset used for its calculation. However we are skeptical about the value of constructing such models for use in daily earthquake analysis. Indeed locating events with this method requires a dense and evenly distributed seismographic network within the area of the model, something not feasible due to the geomorphology limitations of Greece.

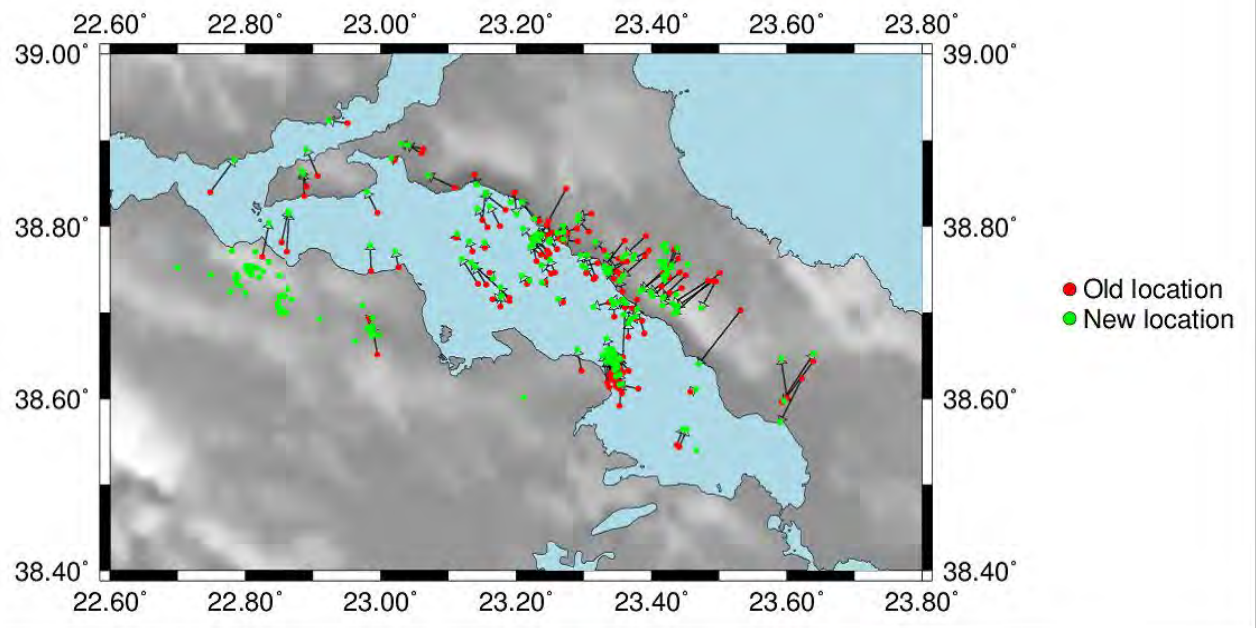

Figure 6 - Locations obtained by the NOA 1D model (red) and the 3D model (green). Only the events located with azimuthal gap lower than $180^{\circ}$ are shown. 


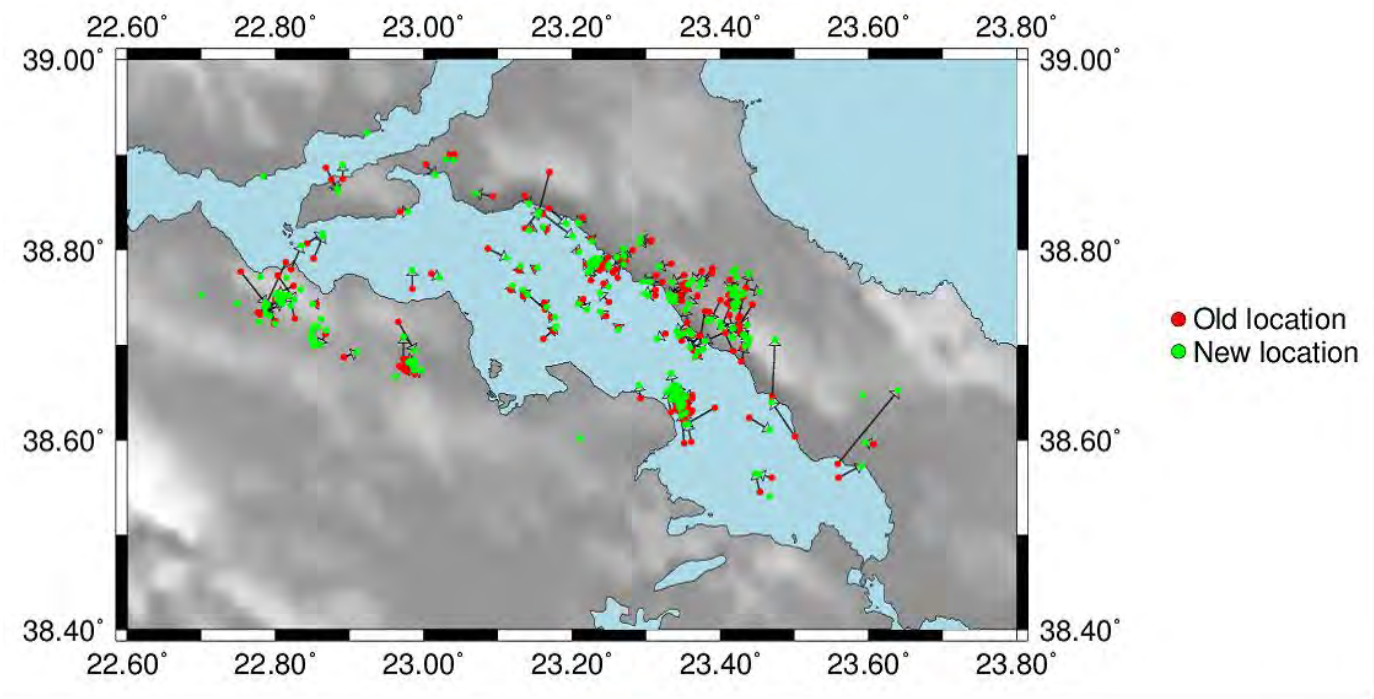

Figure 7 - Locations obtained by the minimum $1 D$ model (red) and the 3D model (green). Only the events located with azimuthal gap lower than $180^{\circ}$ are shown.
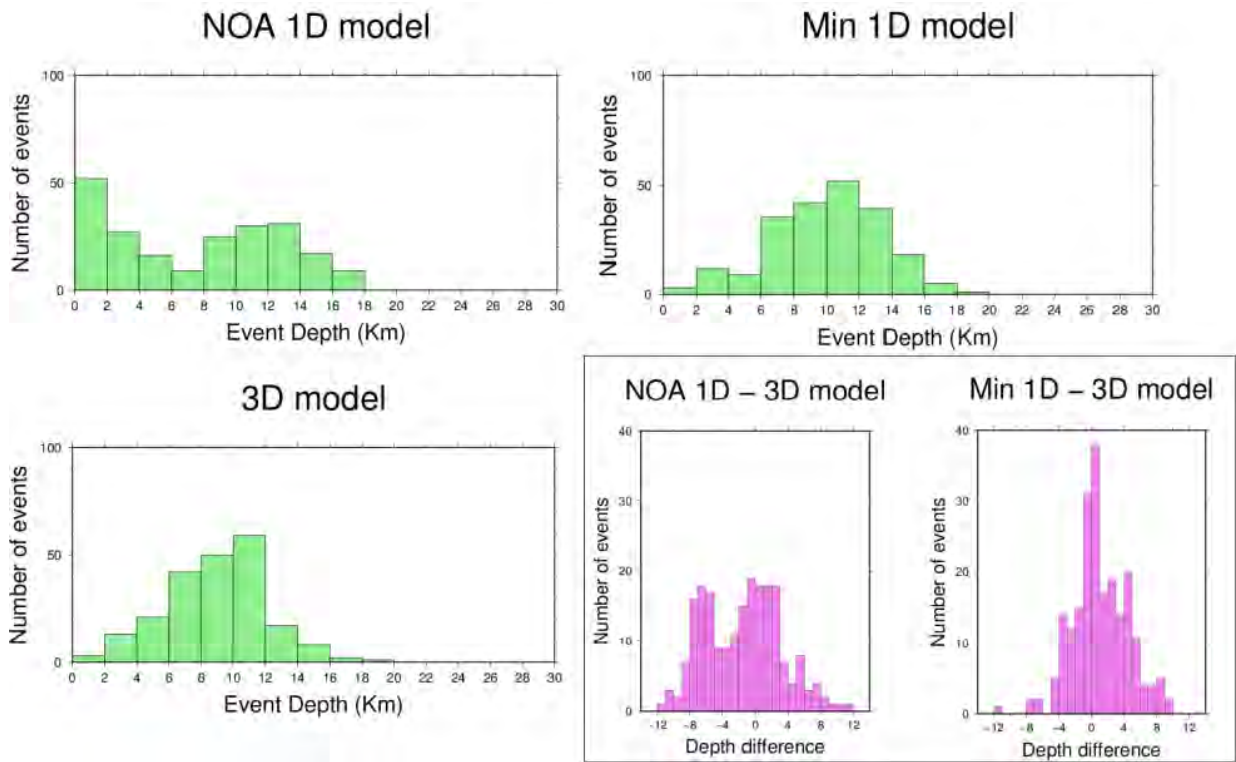

Figure 8 - Depth distribution of the events for the NOA 1D model (top left), the minimum 1D model (top right) and the 3D model (bottom left). Depth differences for the located earthquakes, between the 3D and the 1D models are also presented in this figure (bottom right. 


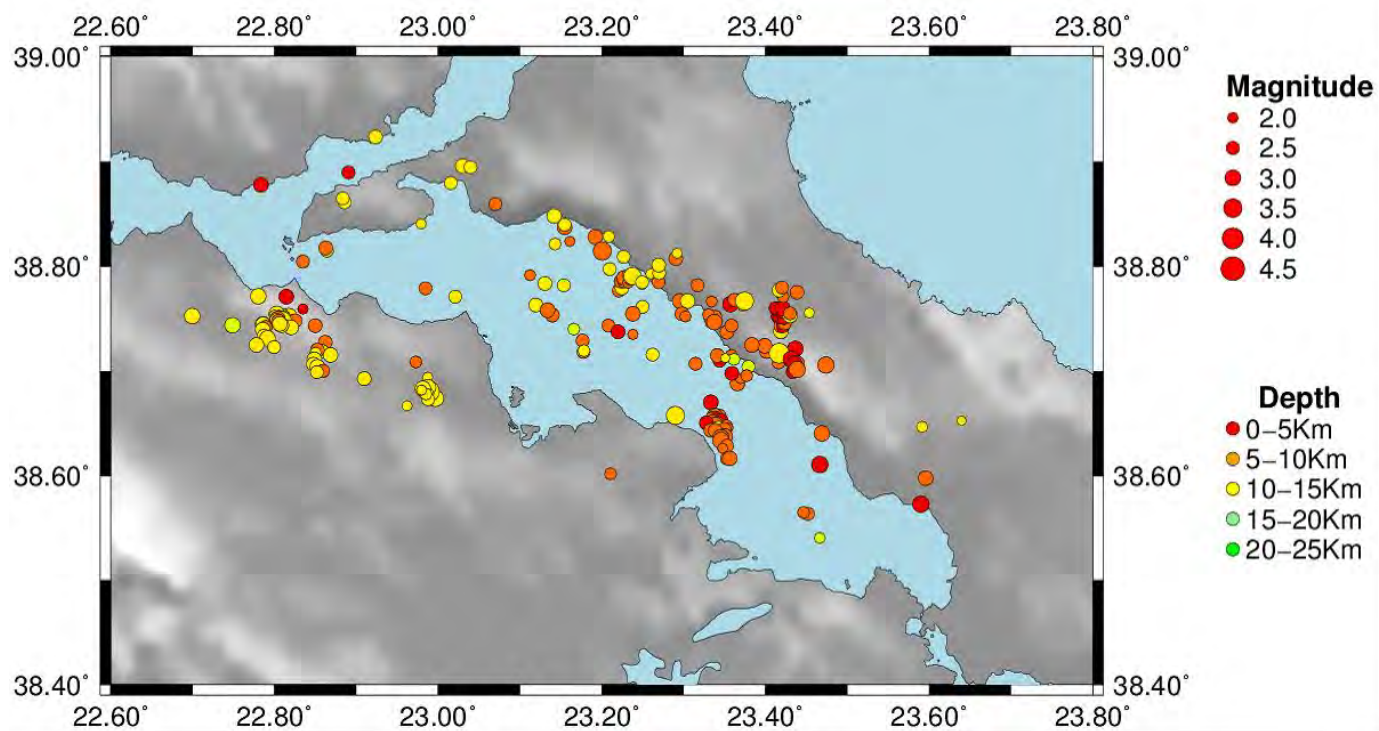

Figure 9 - Event locations map calculated with the use of the local 3D velocity model.

\section{Acknowledgments}

The seismicity data used were gathered by the Hellenic Unified Seismograph Network in the period of 2009-10. We would like to thank the scientific and technical personnel who worked for the creation of this dataset. Thanks are also due to Dr G. Papadopoulos who provided the waveform data of CHLK station for the entire study period. The CHLK station was part of the network established for the monitoring of the metropolitan area of Athens for the Olympic Games of 2004. We would also like to thank Lafarge Beton who provided us with information on the quarry blasts used in that period. The calculation of the 3D local velocity model of the North Euboean Gulf was based on the data funded by the General Secretariat for Research and Technology of Greece, through the research project "AMPHITRITE".

Thanks are due to professor Eleftheria Papadimitriou and professor Antonis Vafidis for their constructive comments which improved the initial version of the paper.

\section{References}

Dewey J.W. 1971. Seismicity studies with the method of joint hypocenter determination, Ph.D. Thesis, University of California, Berkeley, California.

Dewey J.W. 1972. Seismicity and tectonics of western Venezuela, Bull. Seism. Soc. Am. 62, $1711-1751$.

Douglas A. 1967. Joint epicentre determination, Nature 215, 47-48.

Eberhart-Phillips D. 1990. Three-dimensional P and S velocity structure in the Coalinga Region, California, Journal of Geophysical Research 95, 15 343-15 363.

Engdahl E.R.and Lee W.H.K. 1976. Relocation of local earthquakes by seismic ray tracing, $J$. Geophys. Res. 81, 4400-4406.

Ganas A., Roberts G. and Memou P. 1998. Segment boundaries, the 1894 ruptures and strain patterns along the Atalanti Fault, central Greece, Journal of Geodynamics 26, 461-486.

Jordan T. H.and Sverdrup K. A. 1981. Teleseismic location techniques and their application to earthquake clusters in the south-central Pacific, Bull. Seism. Soc. Am. 71, 1105-1130. 
Karastathis V.K.,Ganas A.,Makris J., Papoulia J.,Dafnis P., Gerolymatou E.and Drakatos G. 2007. The application of shallow seismic techniques in the study of active faults: the Atalanti normal fault, central Greece, Journal of Applied Geophysics 62, 215-233.

Karastathis V.K., Papoulia J., Di Fiore B., Makris J., Tsambas A., Stampolidis A. and Papadopoulos G.A. 2011. Deep structure investigations of the geothermal field of the North Euboean Gulf, Greece, using 3-D local earthquake tomography and Curie Point Depth analysis. Journal of Volcanology and Geothermal Research 206, 106-120.

Kissling E., Ellsworth W.L., Eberhart-Phillips D.and Kradolfer U. 1994. Initial reference models in local earthquake tomography, Journal of Geophysical Research 99, 19635-19646.

Kissling E. 1995. Velest User's Guide, Internal report, Institute of Geophysics, ETH, Zurich.

Le Meur H. 1994. Tomographie tridimensionnelle a partir des temps des premieres arrivees des ondes $\mathrm{P}$ et $\mathrm{S}$, application a la region de Patras (Grece), These de Doctorat, Paris VII, France.

Le Meur H., Virieux J.and Podvin P. 1997. Seismic Tomography of the gulf of Corinth: a comparison of methods, Annali di Geofisica, 40, 6, 1-24.

Lomax A. 2005. A reanalysis of the hypocentral location and related observations for the great 1906 California earthquake, Bull. Seism. Soc. Am., 9, $861-877$.

Palyvos N. 2001. Geomorphological study of the broader area of Atalanti, Fthiotis. Ph.D. Thesis. University of Athens, Greece, (in Greek).

Pantosti D., De Martini P.M., Papanastassiou D., Palyvos N., Lemeille F. and Stavrakakis G. 2001. A reappraisal of the 1894 Atalanti earthquake surface ruptures, central Greece, Bulletin of the Seismological Society of America 91, 760-780.

Pavlides S.B., Valkaniotis S., Ganas A., Keramydas D. and Sboras S. 2004. The active fault of Atalanti - re-evaluation with new geological data. Bulletin of the Geological Society of Greece 36, 1560-1567 (in Greek).

Pavlis G.L. and Hokanson N. B. 1985. Separated earthquake location. J. Geophys. Res. 90, $12,777-12,789$.

Pavlis G.L. 1986. Appraising earthquake hypocenter location errors - a complete, practical approach for single-event locations, Bull. Seism. Soc. Am., 76, 1699-1717.

Pavlis G. L. 1992. Appraising relative earthquake location errors, Bull. Seism. Soc. Am. 82, no. 2, 836-859.

Podvin P. and Lecomte I. 1991. Finite difference computation of traveltimes in very contrasted velocity models: a massively parallel approach and its associated tools, Geophys. J. Int., 105, 271-284.

Poulimenos G.and Doutsos T. 1996. Barriers on seismogenic faults in central Greece, J. Geodyn. $22(1-2), 119-135$.

Thurber C.H. 1983. Earthquake locations and three dimensional crustal velocity structure in the Coyote lake area, central California, Journal of Geophysical Research 88, 8226-8236.

Tzanis A., Kranis H.and Chailas S. 2009. An investigation of the active tectonics in central-eastern mainland Greece with imaging and decomposition of topographic and aeromagnetic data, J. Geodyn., doi:10.1016/j.jog.2009.09.042. 